\title{
Review and Identify the Crmrelation with Getting Competitive Advantage, Happiness with Transformative Leadership, Personality Style of Managers with Effectiveness in Credit and Financial Samen Alhojaj institute
}

\author{
Hamidreza Mirali \\ Urban Management Professor, Payam Noor University, Iran.
}

DOI: http://dx.doi.org/10.13005/bbra/1952

(Received: 30 August 2015; accepted: 14 October 2015)

\begin{abstract}
The effect of relationship management with customer on taking competitive advantage, the relationship between the personality style of managers and the level of their effectiveness as well as the impact of transformational leadership on the managers' freshness of the credit and financial institution of Samen Alhojaj are evaluated in this study. The goals of this study are expected in the first area: identify of the dimensions and components of CRM evaluation model and determinate the relationship between the quality of banking services and innovation, in the second area: the role of personality and mental health of the managers in effectiveness and promotion of the job performance and in the third area: the population of the study are all managers and employees and customers of the credit and financial institution of Samen Alhojaj, from that 1400 people were selected as sample. Research methods used in this study consisted of simple random sampling, descriptive and cross correlation. Assumptions of this study were examined by reviewing the reports and documents in the first phase and by distributing questionnaires among samples through inferential statistics, measures of central and Pearson correlation in the second phase. The results show that: In the first area -1 CRM has an effective and positive impact on taking competitive advantage, therefore, it is suggested that emphasis more respectively on the role of location services, promotional factors, physical facilities, service innovation, continuous market research and regular contact with customers. 2- The personality of the managers depend on their mental health, so, it is suggested to hold regular administrative meetings in order to solve workplace problems, psychological consultations to identify possible mental problems between the managers and staff. Security, justice, participation, significance, interesting in work and learn among the ten basic factors of happiness, respectively have the greatest impact on managers' transformational leadership financial of the credit and financial institution of Samen Alhojaj. And personal relationship was not established among the components of interact with colleagues, flexible structure of the organization, positive thinking and self-openness- one of the aspects related to the efficiency and effectiveness of communication has a direct role- with transformative leadership.
\end{abstract}

Key words: Crmrelation, Managers, Financial samen alhojaj institute

The issues of the research include

1 Identification of affecting factors on taking competitive advantage for maintenance and survival of the organization and customers

* To whom all correspondence should be addressed. in order to improve the quality level of services and also considering the solutions to enhance customer loyalty to the organization and

2. Identification of the relationship between personality style of the managers and their effectiveness in order to use the best leadership style to achieve optimum 
efficiency, correct guidance staff to organizational goals and ultimately improve the effectiveness and efficiency of the staff and the system.

3. Identification of the happiness components and assess the impact of each of these components on the transformational leadership in order to improve the environment conditions and, ultimately, happiness and mental health and the comfort of employees, which ultimately leads to reduce costs, to decrease work absences, to achieve to the ideal level of productivity, and to increase the staff comfort.

Accordingly, it is necessary to the preservation and survival of the organization and customers and offer reliable solutions with contingency new leadership styles can conduct the system in the morning to achieve the most effective and the ideal efficient.

Here in regard to a successful organization with very good happiness component can move toward transformational management and to understand correctly the internal needs of staff in order to improve human resource management and thus ensure effective organizational goals, the third hypothesis stated below and tested.

\section{Research hypotheses}

1. There is a significant relationship between the quality of banking services, innovation in organization, efficiency in the organization, responsiveness to customers and relationship management with customers in the credit and financial institution of Samen Alhojaj.

2. There is a significant relationship between the personality style of the bank managers the quality of banking services, innovation in organization, efficiency in the organization, responsiveness to customers and their efficiency.

3. There is a relationship between the between the happiness (self-openness, learning, interest in work, participation, meaningful work, positive thinking, interaction with colleagues, job security, justice and the flexible structure of the organization) and transformational leadership among managers of the credit and financial

\section{institution of Samen Alhojaj. \\ Data analysis methods}

All hypotheses has been tested by SPSS software using statistical methods of central indicators of Pearson correlation test Cronbach's alpha value of this study was calculated $97 \%$.

\section{The results}

In the first area

On the basis of achieved priorities 1 - the role of services 2- the role of non-bank financial services 3 - the location of the place and position of the branches 4 - the role of the human power of the dimension of the ability to provide service and kind of interaction 5 - the role of promotional factors(such as advertisements, flyers, advance sales, public relations and personal sale) the role of physical facilities of the branches had the highest impact on taking competitive advantage.

\section{In the second area}

The results of reviewing the personality characteristics of the managers of Samen Alhojaj institute indicate that managers behavior depends on their characters role and the personality of the managers impact highly on the performance selection and, the rate of absenteeism and staffing and the personality of the managers of each kind depend on their mental health.

So it is necessary to have similar personality traits for effective leadership in similar situations and there should be a fit between people culture (beliefs, ideas and attitudes) and culture of organization (the life of the organization, structure of the organization and work technology).

\section{In the third area}

It can be concluded according to the assumptions of the study that among the ten major factors of happiness respectively the job security, justice, participation, meaningful work, interest in work and learning have the most important and influence in managers transformational leadership in the credit and financial institution of Samen Alhojaj and there is no personal relationship among the component (interaction with colleagues, flexible structure of the organization, positive thinking and self-openness), with transformational leadership in management.

\section{Practical suggestions \\ In the first area}

Because the credit and financial institution of Samen Alhojaj turn their values in a 
good behavior that encourages and supports the innovation, therefore, the technical line which support the practices based on innovation and value should be accepted for the implementation of innovative thinking, and in this regard invest more.

The following practical suggestions sound necessary:

1. Implement market researches and require assessment studies about assess the needs and demands of customers.

2. Contribute to the department of products development and IT departments to create a new electronic banking product, brand development, implementation consulting services about e-commerce advance sales such as discounts activities, competitions and festivals...

3. Put on the agenda of culture, self-service services, trust creation and testing of offered products

4. Promote innovated culture, the quality department, continuous improvement department; take care of complaints and comments and suggestions

5. Providing productive working environment and align the supporting goals of innovation, evaluation systems of employee performance.

6. Codification human resource planning based on strategy innovation and presentation style strategies to increase the efficiency of the institution, according to the funds intermediary is the main task of banks.

7. It is recommended that the employees' performance evaluate regularly to increase the efficiency of institute and increase the ability and individual skills of employees. Create motivate for people by education and poll out the employees $\mathrm{n}$ making decision.

8. Prevent at least of applying untrained staff in direct contact with customers.

\section{In the second area}

The following complaints are provided with regard to the results of assumptions for effective management according to the defined personal style.

1. Hold regular weekly meetings between managers and employees, and express the staff problems in the place.

2. Hold counseling sessions for managers and employees separately and identify mental health problems in both groups

3. Provide job security to retain employees on their jobs and try to satisfy the material and psychological needs of employees

4. Apply participatory and protection management (Participation of workers in organizational various decision-making)

5. Delegate authority and create an office atmosphere free from threats free

\section{In the third area}

The following suggestions are effective to have a transformational leadership for every single happiness component.

\section{In the dimension of self-opening}

Establishing a healthy relationship in the conventional and non-destructive is essential.

\section{In the learning dimension}

Because idealized influence has the highest importance and the most correlated with organizational learning.

\section{Therefore in the development of this agent}

1) It should encourage through emphasize on vision and mission of the institution and empowering the staff and act based on information and support the organizational changes.

2) Leaders encourages followers through create the landscape on employees, create an atmosphere of trust and respect, create a competitive and healthy atmosphere and also they develop the capacity of staff and institutionalize the organizational learning culture at the Institute through creating interaction and balance and use of resource in the stress, tools and methods of acquiring information.

\section{In the positive thinking dimension}

The managers should consider the staff, knowledgeable, valuable and good people and use of key words and positive with staff in daily speech.

\section{In the interest dimension}

The managers who seek committed employees to work should be committed themselves in the first place and look and pay particular attention to their employees and know themselves people's servant. 


\section{In the participation dimension}

Managers must act with participatory management style; share the facts with the group that staffs make effective decisions by providing opinions. Official reduction, increasing the confidence, openness and incentives in the participation will promote success of the institute managers.

\section{In the dimension of significant work}

Managers should consider their employees more valued by creating an environment and share themselves in the progress and success of institute.

\section{In the dimension of interaction with colleagues}

Managers should provide the groundwork to convert implicit knowledge and the evident knowledge through more dialogue and exchange.

\section{In the dimension of job security}

With respect to the increasing feelings of job security cause improves of productivity, costs reduction, quality improvement of the positive attitude, skills improvement, and sincere cooperation of the dynamic managers, therefore, the correct notification is done through meetings, lectures and domestic journals.

\section{In the justice dimension}

It is recommended that the organizing of employee performance information evaluate be informed regularly according to the research results and bonuses carried out based on the results of assessments that the staff by good performance get more results.

\section{REFERENCES}

1. Chan Choi and Sharan Jagpal). Duopoly pricing under risk aversion and parameter uncertainty. Journal of Product and Brand management, 2004; 13(5): 358.

2. Brandenburger, A, Barry J Nalebuff. The right game : use game theory to shape strategy. Harvard Business Review Article, 1995.

3. Meghan Busse. Firm financial condition and airline price war. RAND Journal of Economic 2002; 33(2): 298-318.

4. John Von Neuman and Oskar Morgenstern, Theory of games and economic behavour, 1944.

5. Porter, M.E., The five competitive forces that shape strategy. Harvard Business Review. 2008; 8(l): 81-86

6. Aaker, J ., “ Dimensions of Brand Personality
Journal ofMarketing Research, 1997; XXXIV: 347-356.

7. Bachman, Sheila J., The utilityof selected personal and marketing characteristics in explaining consumer loyalty to selected recreation services, doctoral dissertation, Texas A\&M University, 1988.

8. Bennett, R, Hartel, C.E.J. and McColl- Kennedy, J.R., "Experience as a moderator of involvement and satisfaction on brand loyalty in a businesstobusiness setting 02-314R”, Industrial Marketing Management, 2005; 34: 97-107.

9. Flavian, C., Torres, E., \& Guinaliu, M., Corporate image measurement: A further problem for the tangibilization of Internet banking services. [Electronic version]. The International Journal of Bank Marketing, 2004; 22(4/5): 366-381

10. Bandura, A., Growing primacy of human agency in adaptation and change in the electronic era [Electronic version]. European Psychologist, 2002; 7(1): 2-16.

11. Joseph, M., \& Stone, G., An empirical evaluation of US bank customer perceptions of the impact of technology on service delivery in the banking sector. [Electronic Version]. International Journal of Retail and Distribution Management, 2003; 31(4/5): 190-203, 190-204.

12. Kolodinsky, J.M., Hogarth, J.M., \& Hilgert, M.A.m The adoption of electronic banking by US customers. [Electronic version]. International Journal of Bank Marketing, 2004; 22(4/5), 238276. .

13. Wang, Y-S. Wang, Y-M, Lin H-H, \& Tang, T-I., Determinants of user acceptance of internet banking: An empirical study. [Electronic Version]. International Journal of Service Industry Management, 2003; 14(5): 501-520.

14. Davis, F.D., Perceived usefulness, perceived ease of use, and user acceptance of information technology. [Electronic version]. MIS Quarterly, 1989; 13(3): 319-341

15. Plouffe, C.R., Holland, J.S., \& Vandenbosch, M., Richness versus parsimony in modeling technology adoption decisions - Understanding merchant adoption of a smart card-based payment system. [Electronic version]. Information Systems Research, 2001; 12(2): 208-228

16. Moore, G. C. \&Benbasat, I., "Integrating diffusion of innovations and theory of reasoned action models to predict utilization of information technology by end-users", information systems management, 1996; 4(1): $132-146$

17. Naranjo Valencia, J. C., Valle, R. S. \& Jimen ez, 
D. J., "Organizational culture as determinant of product Innovation”, Journal of Innovation Management. 2010; 13(4): 466-480.

18. Ragins, E. J. \& Greco, A. J., "Customer relationship management and e-business: more than a software solution”, Review of Business, 2003; 24(1): 25-30.

19. Ross, David F., "E-CRM from a supply Chain management perspective", Information SystemsManagement, 2005; 4(1): 132 -146.

20. Tan, X., Yen, D. C. \& Fang, X., “Internet integrated customer relationship management: a keysuccess factor for companies in the ecommerce arena”, Journal of Computer Information Systems, 2002; 42(3), pp. 77-86.

21. Guleri, T., "CRM throughout the enterprise: how to make it happen”, Call Center Solutions, 2000; 18: 44 -46.

22. Hu, P. J., Chau, O. R. \& Sheng, K. Y. “Examining the technology acceptance model using physician accepta nce of telemedicine technology”, Journal of Management Information Systems,1999; 16(2): 91 - 112.

23. Kassanoff, B., "Build loyalty into your Ebusiness, in proceedings of DCI customer relationship management conference”, Boston, MA, 2000; 27-29.

24. Li-Hua, R., Wilson, J., Aouad, G. \& Li, X., "Strategic aspects of innovation and internationalization in higher education The Salford PMI2 experience”, Journal of Chinese Entrepreneurship, 2011; 3(1): 8-23.

25. Moore, G. C. \&Benbasat, I., "Development of an instrument to measure the perception of adopting an information technology innovation”, Information System Research, 1991; 2(1), pp.192 - 222.

26. Moore, G. C. \&Benbasat, I., “Integrating diffusion of innovations and theory of reasoned action models to predict utilization of information technology by end-users", information systems management, 1996; 4(1): $132-146$

27. Naranjo Valencia, J. C., Valle, R. S. \& Jimenez, D. J., “Organizational culture as determinant of product Innovation”, Journal of Innovation Management. 2010; 13(4): 466-480.

28. Ragins, E. J. \& Greco, A. J., "Customer relationship management and e-business: more thana software solution", Review of Business, 2003; 24(1): 25-30.

29. Ross, David F., "E-CRM from a supply Chain management perspective”, Information Systems Management, 2005; 4(1): 132 -146.

30. Tan, X., Yen, D. C. \&Fang, X., “Internet integrated customer relationship management: a keysuccess factor for companies in the ecommerce arena", Journal of Computer Information Systems, 2002; 42(3): 77-86.

31. Winer, R. S., "A framework for customer relationship management”, California Management Review, 2001; 43(4): 89-105.

32. Zablah, A. R., Bellenger, D. N. \& Johnston, W. J., “An evaluation of divergent perspectives oncustomer relationship management: towards a common understand ding of an emerging phenomenon”, Industrial Marketing Management, 2004; 33(4): 475-89

33. Li-Hua, R., Wilson, J., Aouad, G. \& Li, X., "Strategic aspects of innovation and internationalization in higher education The Salford PMI2 experience", Journal of Chinese Entrepreneurship, 2011; 3(1): 8-23.

33. Moore, G. C. \&Benbasat, I., "Development of an instrument to measure the perception of adopting an information technology innovation", Information System Research, 1991; 2(1): 192 222.

34. Andersen. John Aarum, "Intuition In Managers"; Journal of Managerial Psychology, 2000; 15(1): 46-67.

35. Bradley. John H. \& Herbert.Fredric J., “The Effect of Personality Type on Team Performance"; Journal of Management Development, 1997; 10(5): 337-353.

36. Flanum. Romana, Relationship between Personality Type \& the Ability to be a Change Agent; The Graduate College (University of Wisconsin- Stout). 